\title{
III Congresso Internacional

\section{O USO DO JOGO SIMCITY NO ENSINO DE GEOGRAFIA: UMA PROPOSTA DIDÁTICA METODOLÓGICA EM UMA ESCOLA MUNICIPAL DE SÃO GONÇALO DO AMARANTE-RN}

Apresentação: Comunicação Oral

Gilberto Ivens de Araújo Tavares ${ }^{1}$; João Batista dos Santos²; Maria Luiza de Medeiros Galvão ${ }^{3}$

\section{Resumo}

Com o atual crescimento e desenvolvimento dos avanços tecnológicos, surge a necessidade de se aplicar novas metodologias para o ensino e o aprendizado dos alunos. Desta forma, é de fundamental importância a aplicação de novos métodos que tende a tornar o ensino mais eficiente, neste caso a utilização de jogos nesse processo possui um alto valor educativo e motivador. Nesse contexto, o jogo vem como um estímulo tanto para melhorar a compreensão do conteúdo, quanto para o crescimento e o desenvolvimento intelectual do aluno e também é fundamental para atingir a responsabilidade e a maturidade. É mais uma forma de levar o conteúdo aos alunos motivando-os a estudar de maneira envolvente. Salienta-se que, a inclusão de novas metodologias e modelos didático-pedagógicas que busquem auxiliar nas necessidades encontradas no processo de ensino aprendizagem na realidade escolar é de grande importância e também necessário para que possua maior envolvimento dos alunos.

Visando a melhoria de compreensão e aprendizado dos alunos, de modo que esse aprendizado não se torne apenas saber ou conhecer algo, mas que possa incluir outros níveis de conhecimento que resultem em habilidades e atitudes no sentido da formação dos mesmos como seres humanos, É que surgiu o interesse de pesquisar, dentre as muitas possibilidades existentes para inovar no ensino, apresentar algumas reflexões sobre a utilização de jogos e avaliar de forma concreta uma experiência neste sentido, especialmente para o ensino de Geografia. Desse modo, o presente projeto tem como objetivo geral analisar se a utilização do jogo Simcity, tem facilitado a compreensão do processo de aprendizagem, o rendimento e a frequência dos alunos do $8^{\circ}$ ano do ensino fundamental da Escola Municipal Roberto Freire, localizada no município de São Gonçalo do Amarante.

Palavras-Chave: Ensino de Geografia, aprendizagem, jogos, Simcity

\footnotetext{
${ }^{1}$ Licenciatura em Geografia, IFRN, ivens_gilberto@yahoo.com.br

${ }^{2}$ Licenciatura em Geografia, IFRN, ivens_gilberto@yahoo.com.br

${ }^{3}$ Doutoranda, IFRN, luiza.galvao@ifrn.edu.br
} 


\section{Introdução}

Nos dias de hoje, grande parte dos alunos sentem dificuldades em compreender alguns conceitos trabalhados em sala de aula, além disso muitos tem dificuldades em transpor tais saberes para sua própria realidade. Existe uma certa carência em suprir as necessidades de mudanças na escola.

A escola não mudou, ou pelo menos não se adequou as rápidas mudanças tecnológi2cas advinda da revolução técnico cientifica informacional, os modelos didáticos não evoluíram, entretanto as metodologias de avaliações continuam as mesmas.

Com o atual crescimento e desenvolvimento dos avanços tecnológicos, surge a necessidade de se aplicar novas metodologias para o ensino e o aprendizado dos alunos. Desta forma, é de fundamental importância a aplicação de novos métodos que tende a tornar o ensino mais eficiente, neste caso a utilização de jogos nesse processo possui um alto valor educativo e motivador.

Nesse contexto, o jogo vem como um estímulo tanto para melhorar a compreensão do conteúdo, quanto para o crescimento e o desenvolvimento intelectual do aluno e também é fundamental para atingir a responsabilidade e a maturidade. É mais uma forma de levar o conteúdo aos alunos motivando-os a estudar de maneira envolvente.

Salienta-se que, a inclusão de novas metodologias e modelos didáticos pedagógicos que busquem auxiliar nas necessidades encontradas no processo de ensino aprendizagem na realidade escolar é de grande importância e também necessário para que possua maior envolvimento dos alunos.

De acordo com Castellar e Villena, (2010) os jogos são situações de aprendizagens que possibilitam a interatividade entre aluno e professor, e aluno -aluno, estimulam a cooperação, tornando o ambiente escolar mais descontraído, auxiliando na superação do egoísmo infanto juvenil, ao mesmo tempo em que ajudam na formação de conceitos.

Ademais, as atividades com jogos rompem com o paradigma tradicional ainda mantido pelos professores nos dias de hoje. Essas atividades inovadoras conduzem o aluno para um processo de assimilação ainda maior, possibilitando a oportunidade de melhorar sua capacidade cognitiva, construindo um raciocínio logico e tornando o processo de aprendizagem mais significativo. No entanto, para se ter um desenvolvimento satisfatório do ponto de vista cognitivo, a inclusão de jogos na escola é imprescindível o planejamento prévio. Antes de disponibilizá-los para o alunado, é importante analisar a variedade e a quantidade disponível para avaliar se todos podem jogar ao mesmo tempo ou se é necessário fazer um rodízio. Além disso, os jogos devem ser atraentes e bonitos e ter bom acabamento. 
Segundo Callai (2005), os jogos no ambiente de sala de aula devem ser desenvolvidos e trabalhados com cautela, de forma a contribuir para o processo de ensino aprendizagem da criança, principalmente quando visar trabalhar algum conteúdo escolar, ou quando dentro do ambiente da escola. Deve-se evitar, por exemplo, que a atividade possa se tornar um material que desperte uma competição negativa, ou que se constitua numa mera atividade recreativa.

Diante das questões explicitadas, ressalta-se, portanto, a importância de pesquisas que complementem o conhecimento de novas práticas prazerosas nas salas de aula como a utilização de jogos no ensino de geografia. Deste modo, o desafio é também, apresentar propostas metodológicas alternativas que contribuam com a formação continuada de professores que atuam no ensino fundamental e médio, bem como contribuir para a melhoria do ensino de geografia.

Visando a melhoria de compreensão e aprendizado dos alunos, de modo que esse aprendizado não se torne apenas saber ou conhecer algo, mas que possa incluir outros níveis de conhecimento que resultem em habilidades e atitudes no sentido da formação dos mesmos como seres humanos, É que surgiu o interesse de pesquisar, dentre as muitas possibilidades existentes para inovar no ensino, apresentar algumas reflexões sobre a utilização de jogos e avaliar de forma concreta uma experiência neste sentido, especialmente para o ensino de Geografia.

Desse modo, o presente artigo tem como objetivo geral analisar se a utilização do jogo tem facilitado a compreensão do processo de aprendizagem, o rendimento e a frequência dos alunos do $8^{\circ}$ ano do ensino fundamental da Escola Municipal Roberto Freire.

Os objetivos específicos são os seguintes: compreender a importância do uso de jogos no ensino de geografia, avaliar a interação entre professor aluno e aluno- aluno através da utilização do jogos no ensino de geografia, verificar se o uso dos jogos tem favorecido a participação ativa dos alunos em atividades escolares, sendo uma ferramenta eficaz no combate ao baixo rendimento e evasão escolar.

A questão central que se coloca é, o uso do jogo virtual Simcity tem contribuído para compreensão dos conceitos geográficos e melhorado o rendimento dos alunos do $8^{\circ}$ ano do Ensino Médio da Escola Municipal Roberto Freire ou apenas os entretém?

Partindo dessa problemática temos as seguintes hipóteses: os jogos são objetos indispensáveis para o desenvolvimento intelectual dos alunos, as atividades com jogos atraem o aluno provocando no mesmo o desenvolvimento de habilidades que enriquecem o processo de ensino aprendizagem, os jogos virtuais estimulam a participação, interatividade, cooperação, análise crítica e motivação dos alunos.

A proposta pedagógica utilizada em sala de aula, com os alunos entrevistados, está calcada em um viés construtivista e propõe que o aluno participe ativamente do próprio aprendizado, 
mediante a experimentação, a pesquisa em grupo, o estimulo a dúvida e o desenvolvimento do raciocínio, entre outros procedimentos. A partir de sua ação, ele vai estabelecendo as propriedades dos objetos e construindo as características do mundo.

\section{Fundamentação Teórica}

Nos dias de hoje, grande parte dos alunos sentem dificuldades em compreender alguns conceitos trabalhados em sala de aula, além disso muitos tem dificuldades em transpor tais saberes para sua própria realidade. Existe uma certa carência em suprir as necessidades de mudanças na escola.

A escola não mudou, ou pelo menos não se adequou as rápidas mudanças tecnológicas advinda da revolução técnico cientifica informacional, os modelos didáticos não evoluíram, entretanto as metodologias de avaliações continuam as mesmas.

Com o atual crescimento e desenvolvimento dos avanços tecnológicos, surge a necessidade de se aplicar novas metodologias para o ensino e o aprendizado dos alunos. Desta forma, é de fundamental importância a aplicação de novos métodos que tende a tornar o ensino mais eficiente, neste caso a utilização de jogos nesse processo possui um alto valor educativo e motivador.

Nesse contexto, o jogo vem como um estímulo tanto para melhorar a compreensão do conteúdo, quanto para o crescimento e o desenvolvimento intelectual do aluno e também é fundamental para atingir a responsabilidade e a maturidade. É mais uma forma de levar o conteúdo aos alunos motivando-os a estudar de maneira envolvente.

Salienta-se que, a inclusão de novas metodologias e modelos didáticos pedagógicos que busquem auxiliar nas necessidades encontradas no processo de ensino aprendizagem na realidade escolar é de grande importância e também necessário para que possua maior envolvimento dos alunos.

Segundo Callaio (2005), os jogos no ambiente de sala de aula devem ser desenvolvidos e trabalhados com cautela, de forma a contribuir para o processo de ensino aprendizagem da criança, principalmente quando visar trabalhar algum conteúdo escolar, ou quando dentro do ambiente da escola. Deve-se evitar, por exemplo, que a atividade possa se tornar um material que desperte uma competição negativa, ou que se constitua numa mera atividade recreativa.

Dentro dessa perspectiva, o ensino de geografia deve ter como finalidade básica de ação, trabalhar o aluno juntamente com suas referências adquiridas na escola e sistematizá-las em contato com a sociedade, com o cotidiano para assim criar um pensar geográfico que leve em consideração a análise da natureza com a sociedade e como estas se relacionam e quais as dinâmicas resultantes deste relacionamento. Diante disso, Danneli afirma 
O ensino de geografia pode levar os alunos a compreenderem de forma mais ampla a realidade, possibilitando que nela interfiram de maneira mais consciente e propositiva. Para tanto, porém, é preciso que os educandos adquiram conhecimentos, dominem categorias, conceitos e procedimentos básicos com os quais este campo de conhecimento opera e constitui suas teorias e explicações, de modo a poder não apenas compreender as relações socioculturais e o funcionamento da natureza às quais historicamente pertence, mas também conhecer e saber utilizar uma forma singular de pensar sobre a realidade, ou seja, o conhecimento geográfico. (DANNELI,2007, P.78)

Assim, para que os alunos possam compreender o espaço produzido, é essencial entender as relações entre os homens, tudo depende de que forma eles se organizam para a produção e distribuição dos bens materiais, os espaços que se produzem vão adquirindo determinadas formas que materializam essa organização no ensino da geografia.

\section{Metodologia}

Para a realização deste trabalho foi feito um levantamento bibliográfico para a compreensão e importância do uso de jogos no ensino de geografia, em seguida foi desenvolvido um estudo de caso, baseado numa análise quantitativa e qualitativa, numa turma do $8^{\circ}$ ano único do Ensino Fundamental ano de uma escola pública, num total de 35 alunos.

Pretendeu-se com esta pesquisa saber se a utilização do jogo como recurso contribuiu para a consolidação de conhecimentos e motivação em Geografia por parte dos alunos. Para tanto foi realizado a elaboração de um inquérito aplicado aos alunos da turma, o registo de opiniões/sugestões por parte dos alunos sobre o recurso, e por fim o inquérito final.

Para turma do $8^{\circ}$ ano único da Escola Municipal Roberto Freire foram aplicados os jogos e respectivas fichas de trabalho relacionadas aos conhecimentos da disciplina de geografia. Os alunos trabalharam de forma grupal e individual, prevalecendo os trabalhos em grupo. Os jogos foram utilizados com base nos conteúdos ministrados em sala de aula, servindo para ajudar e tentar aproximar os alunos do conteúdo de modo a facilitar a aprendizagem dos mesmos.

\section{Resultados e Discussão}

"Há poucas décadas o ensino de geografia apresentava um caráter meramente descritivo e propositalmente alienante" (CAVALCANTI,2002, p.33). Durante vários anos, o ensino de geografia se resumia a decorar o nome de rios, tipos de relevo, capitais de países e estados. Este tipo de pensamento levou a ciência geográfica para longe da realidade dos atores participantes do processo de ensino e aprendizagem. De acordo com Vessentini (1992): 
geografia, algo que nos remete à prática de um ensino de geografia mnemônico, confuso e sem objetivo para a realidade, para o conhecimento do espaço. (VESSENTINI, 1992.p.47)

Essas características de memorização de diversos conceitos geográficos não deixaram de fazer parte do conteúdo curricular da Geografia em sua relevância, mas decorá-la de forma descontextualizada dificulta o questionamento do discente, no que se refere a seu papel enquanto cidadão propositivo e atuante no mundo.

Segundo Cavalcanti (2002), nos anos finais da década de 1970 este paradigma começa a ser mudado, pois surge um momento de intensas transformações no âmbito da pesquisa e ensino, este momento ficou conhecido como Movimento de Renovação da Geografia. A partir deste momento, muitos foram os caminhos escolhidos. Isso ocorre para se fazer uma análise crítica da fundamentação teórico-metodológico da ciência geográfica e para se propor alternativas ao modo de trabalhar essa ciência enquanto matéria escolar.

Dessa forma, de acordo com Oliveira (1989):

As reformulações da ciência geográfica levaram, então, a alteração significativa no campo do ensino de Geografia, mesmo porque alguns dos pesquisadores mais expressivos circularam nas duas áreas de investigações. Atestam isso os inúmeros trabalhos produzidos, nas últimas décadas, que denunciaram as fragilidades de um ensino com base na Geografia Tradicional e que propuseram o ensino de uma Geografia nova. No Brasil, o movimento de renovação do ensino de Geografia faz parte de um conjunto de reflexões mais gerais sobre os fundamentos ideológicos e políticos da ciência geográfica, iniciando no final da década de 1970. (OLIVEIRA,1989, p.34)

Nesse contexto, aparece a geografia crítica que teve um papel fundamental para a melhora do processo de ensino e aprendizagem, pois ela, segundo Vessentini (1992), concebe o espaço geográfico como um espaço social formado a partir do movimento dialético, repleto de lutas e conflitos sociais. O mesmo autor ainda reforça que:

Essa geografia radical ou crítica coloca-se como ciência social, mas estuda também a natureza como recurso apropriado pelos homens e como uma dimensão da história, da política. No ensino, ela se preocupa com a criticidade do educando e não com "arrolar fatos" para que ele memorize. (VESSENTINI,1992a, p.22).

Nota-se, que este novo paradigma foi um passo importante no ensino de geografia, todavia, é preciso ressaltar que ainda nos dias de hoje muitos professores que se auto denominam "críticos", continuam a praticar uma didática tradicional como a utilização do livro didático exclusivamente como única fonte de conhecimento geográfico, uso de avaliações baseados no método de memorização de dados como nomes de rios, nomes de capitais, entre outras práticas que não contribuem para um processo de reflexão e criticidade nos seus alunos. 
Segundo Castelar (2010) É imprescindível pensar sobre as metodologias utilizadas em salas de aula, sendo que é de fundamental importância saber utilizar essas metodologias para a inserção dos alunos no seu contexto social, relacionando a teoria da prática.

Assim, para que os alunos possam compreender o espaço produzido, é essencial entender as relações entre os homens, tudo depende de que forma eles se organizam para a produção e distribuição dos bens materiais, os espaços que se produzem vão adquirindo determinadas formas que materializam essa organização no ensino da geografia.

Atualmente, temos visto que muitos estudantes do ensino fundamental e do ensino médio tem apresentado muitas dificuldades no que se refere aos conceitos trabalhados em sala de aula e também sentem dificuldades em relacionar os conteúdos ministrados com a sua própria realidade.

Há também diversos desafios que são encontrados pelos professores na sua vida profissional; ultimamente, este desafio se torna mais evidente, sobretudo, devido às grandes transformações que o ensino vem passando.

Diante disso, o educador precisa definir por meio do planejamento os seus objetivos, as estratégias e métodos a serem trabalhados com os alunos, conduzindo os, até os conhecimentos, através de uma mediação didática, seja com a utilização do livro didático ou de outras formas inovadoras de ensino.

Segundo Castelar (2010), o uso de jogos contribui para um ensino que confere ao aluno um papel ativo na construção dos novos conhecimentos, pois permite a interação com o objeto a ser conhecido, estimulando assim um intercâmbio de ideias e hipóteses diferentes, além de possibilitar conflitos, desequilíbrios e a construção de novos conhecimentos, tornando o aluno apto para o aprender a fazer, o relacionar, o constatar, o comparar, o construir e o questionar.

Dessa forma, entende-se que a elaboração e execução de jogos em sala de aula podem ser imprescindíveis ferramentas no auxílio do processo de ensino e aprendizagem, pois ao ser pensado e elaborado com fins didáticos, ele pode contribuir de uma forma rica para que o professor investigue os processos e as dificuldades apresentadas pelos alunos durante sua resolução.

Nesse contexto, Macedo (2010) reforça:

O interessante na aplicação dos jogos é perceber como os alunos interagem com essas atividades desafiadoras, diagnosticando quais habilidades cognitivas ela apresenta ou precisa desenvolver- descentralização espacial, reversibilidade, conservação abstração de pensamento, etc. que conhecimentos prévios ela possui sobre as noções sócio espaciais, que precisam ser sistematizadas para que amplie seu nível de conhecimento. (MACEDO,2010, p.54)

Todas essas considerações demostram a importância de se repensar o papel docente, para que este torne-se mais crítico, autônomo, capaz de organizar suas aulas, levando em conta as 
diferentes etapas de desenvolvimento cognitivo dos seus alunos, a necessidade do diagnóstico dos conhecimentos prévios, bem como o conhecimento devido sobre as habilidades cognitivas indispensáveis para o desenvolvimento intelectual dos seus alunos.

Partindo desses pressupostos, utilizou-se o jogo SimCity, como ferramenta metodológica de ensino visando uma aprendizagem significativa aos alunos. A utilização desse jogo, deve-se ao fato de que a geração de hoje, desde cedo, manipula aparelhos eletrônicos com facilidade, em seus ambientes domésticos. Outro fator que também possibilita tal ocorrência decorre do fato de que os ambientes gerados por aplicativos informáticos dinamizam os conteúdos curriculares e potencializam o processo pedagógicos.

Nesse contexto, a utilização do jogo eletrônico SimCity, disponível em plataforma mobile (dispositivos móveis), é um recurso didático a ser utilizado para a aquisição dessas competências, pois o mesmo pode abranger os estudos das categorias geográficas como como território, paisagem, lugar, região, espaço geográfico. Esse jogo permite a criação de cidades moldados nos processos geográficos, o que vem a promover a interação do aluno com fatores reais de modo virtual. Dessa forma, permite reproduzir em sala de aula situações que não poderiam ser realizadas na vida real, mas que são possíveis na simulação.

No decorrer do jogo além do estudo das categorias geográficas, o aluno podia observar outras vertentes, como a degradação do meio ambiente, e o desenvolvimento do meio urbano, considerando o fato de poder optar por construir zonas comerciais, residenciais, e industrial. E tendo que lidar com as constantes reclamações da população da sua cidade por melhores condições de vida e serviços, implementando assim todo um cenário tipicamente da vida real.

Após o uso do jogo pelos alunos do $8^{\circ}$ ano do ensino fundamental, realizou-se uma pesquisa com a aplicação de questionário aberto com as seguintes perguntas: você considera importante a utilização de novas técnicas didáticas no processo de ensino da disciplina de Geografia? Você acha interessante estar envolvido em conjunto ao Professor e toda a turma de sala de aula na confecção de novas e diferentes atividades que busquem facilitar a aprendizagem? O jogo virtual utilizado foi de fácil compreensão? Você deseja que essa metodologia seja introduzida no seu cotidiano?

Por meio do questionário foi possível identificar à reação dos alunos da atividade proposta, em relação a primeira questão:88\% dos alunos entrevistados consideraram importante a utilização de jogos eletrônicos no processo de ensino; $100 \%$ dos alunos acharam interessante interagir com a turma e professor na prática dos jogos com os colegas e professor; Para $85 \%$ dos alunos a atividade facilitou a aprendizagem de temas em geografia que eles achavam complexos de entendimento; $22 \%$ dos alunos entrevistados consideraram o jogo de difícil compreensão, demonstrando uma certa de dificuldade inicial na compreensão da dinâmica do jogo; Já em relação a última pergunta, notou- 
se que $90 \%$ dos alunos desejam que essa metodologia de ensino com jogos venha ser introduzida no seu cotidiano.

O principal objetivo da utilização desse jogo foi o crescimento e desenvolvimento intelectual do aluno, levando-os a tornarem-se indivíduos responsáveis e motivados a transformar sua própria realidade, tornando-se mais críticos. Com a aplicação dessa atividade lúdica percebeu-se que a interação entre professor e aluno aumentou, e que o processo de assimilação dos conteúdos se tornou mais fácil. Desse modo, constatou-se que o papel do professor deve ser sempre de mediador, para tanto o mesmo deve buscar planejar o conteúdo da melhor maneira possível a fim de desenvolver o raciocínio dos alunos.

\section{Conclusões}

Na sala de aula a utilização de jogos deve tornar o ensino dos conceitos geográficos mais eficientes e com maior valor pedagógico e educativo, devendo assim ser estimulado a proporcionar aos alunos uma melhor compreensão do conteúdo e não ser apenas mais um jogo. Com isso o lúdico passa a ser uma estratégia a ser usada como estimulante na construção do conhecimento.

No ensino de Geografia as atividades lúdicas devem tratar de questões e fatores das mais diversas áreas como distribuição geográfica, mapas, localização territorial, ou seja, não somente temas ligados a assuntos físicos, mas também a acontecimentos políticos que exerçam influência sobre a população de um modo geral.

$\mathrm{O}$ ambiente a ser recriado pelos jogos deve entrar em contato com determinado tipo de acontecimento ou processo, e as possíveis evoluções que a sociedade passou, fazendo com que o aluno possa acompanhar essas transformações. Conforme os Parâmetros Curriculares Nacionais (PCNs), o professor deve evitar as aulas tradicionais, utilizando recursos didáticos que estimulem os alunos (aulas práticas, utilização de maquetes, fotografias aéreas, imagens de satélite, recursos lúdicos, entre outros).

Este artigo buscou analisar a contribuição dos jogos eletrônicos no processo de ensinoaprendizagem, mas especificamente na disciplina de Geografia. Para tal, realizou-se um levantamento bibliográfico em livros, sites especializados e artigos científicos voltados para o tema abordado.

Pode se constatar que os jogos eletrônicos são uma excelente proposta metodológica para o Ensino de Geografia ou de qualquer outra Ciência. Para tanto faz-se necessário a figura do professor como mediador dessa ferramenta no processo de ensino-aprendizagem. Diante dos argumentos expostos, o uso do jogo Simcity como recurso metodológico destaca-se em relação a outros, pois 
esse proporcionou uma maior interatividade entre o aluno e a tecnologia e consequentemente entre os próprios

Nesse sentido, notamos que a atividade com jogos realizada na escola Municipal Roberto Freire teve repercussão positiva, pois, a maioria dos alunos achou a aula dinâmica e divertida, alunos de outras salas mostraram grande interesse em participar da atividade e foram incluídos. Salienta-se que os alunos interagiram de maneira cordial.

\section{Referências}

ANTUNES, Celso. Inteligências múltiplas e seus jogos: introdução, v. 1. Petrópolis: Vozes, 2006.

BRASIL. Secretaria de Educação Fundamental. Parâmetros Curriculares Nacionais para Geografia $3^{\mathbf{o}}$ e $4^{\mathbf{0}}$ ciclos (5 a $\mathbf{8}^{\mathrm{a}}$ séries). Brasília: MEC, 1998.156p.

CAVALCANTI, L. de S. Geografia e prática de ensino. Goiânia: Editora Alternativa, 2002.

CASTELlAR, Sônia; VILHENA, Jerusa. Ensino de Geografia. São Paulo: Cengage Learning, 2010. (Coleção Ideias em Ação).

CALLAI, H. C. Aprendendo a ler o mundo: a Geografia nos anos iniciais do ensino fundamental. Cad. Cedes, Campinas Cad. vol. 25, n. 66, 2005, p. 227-247. Disponível em http://www.cedes.unicamp.br.acessoem25 de março 2016

CALLAI, Helena Copetti. A formação do profissional da Geografia. 2. ed. Ijuí (RS): Unijuí, 2006.

DANELLI, Sônia Cunha de S. (org.). Projeto Araribá: Geografia: Ensino Fundamental. 2 ed. São Paulo: Moderna, 2007.

GADOTTI, Moacir. A organização do trabalho na escola: alguns pressupostos. São Paulo: Ática, 1993.

MACEDO, Lino de, PETTY, Ana Lúcia Sicoli, PASSOS, Norimar Christe. Aprender com jogos e situações problema. Porto Alegre: Artmed, 2000. 
OLIVEIRA, Ariovaldo U. de (org.). Para onde vai o ensino de Geografia? São Paulo: Contexto, 1989.

PASSINI, Elza Yasuko. Prática de ensino de Geografia e estágio supervisionado. São Paulo: Contexto, 2007.

PONTUSCHKA, Nídia Nacib. Novos Caminhos da Geografia. São Paulo: Contexto, 2001.

SILVA, L. G. Jogos e situações-problema na construção das noções de lateridade, referências e localização espacial. In: CASTELLAR, S. Educação geográfica: teorias e práticas docentes. São Paulo: Editora Contexto, 2006.

VESENTINI, José William. Geografia crítica e ensino. In VESENTINI, José William. Para uma Geografia Crítica na Escola. São Paulo: Ática, 1992 